\title{
The endoscopic pneumatic balloon dilation in treating achalasia in a Moroccan center
}

\author{
Mounia El Yousfi, Nada Lahmidani, Adil Ibrahimi, Dafr-Allah Benajah \\ Department of Hépato-Gastroenterology, University Sidi Mohammed Ben Abdillah, Fez, Morocco \\ Email: elyousfimounia2005@yahoo.fr
}

Received 13 August 2012; revised 15 September 2012; accepted 23 September 2012

\begin{abstract}
Aim of the work: Achalasia is a rare pathology whose physiopathogenesis is mysterious. The treatment is based on endoscopic pneumatic dilation (PD) and surgery. The aim of our work is to show our experiment about endoscopic pneumatic dilation as the principal treatment suggested for patients presenting achalasia. Material and Method: It is a retrospective study relating 21 cases of achalasia indexed between 2002 and 2007. The remission was judged on Eckardt's clinical criteria. If the symptoms persist after three episodes of PD, there's a therapy failure and the patients were then proposed to surgery or recurrent DP. The results: The Middle Age at the time of diagnosis was of $44 \pm 10,66$ years ( 20 to 76 ). The sex ratio was $1,3(12 \mathrm{M} 9 \mathrm{~F})(p=0.5)$. The diagnosis of achalasia is based on imaging, endoscopy and manometric arguments. The PD of the cardia was proposed in first intention, except two patients who were treated 6 and 15 years before by surgery. 38 dilations were performed for 21 patients with an average of 1.8 PD per patient [1-6]. The rate of good answers after the third episode of PD was about $90.47 \%$ (19 patients). There was no complication of the PD. In plain-varied analysis, no predictive factor of good answers to PD was retained. Conclusion: PD is an effective cure with a negligible morbidity and no mortality. The surgery is reserved for the failures of pneumatic dilation.
\end{abstract}

Keywords: Achalasia; Esophagus; Treatment; Pneumatic Dilation

\section{INTRODUCTION}

The primary achalasia of the esophagus is a rare disease known since a long time. In 1647, Thomas Willis [1] reported the first case of a patient treated for 15 years by removing the obstruction of his cardia using a rod with whalebone and a ball sponge fixed to its end. The rarity of the disease did not fully permit to understand the pathogenic mechanisms. The most recent theories suggest autoimmune, infectious and genetic factors. The advent of esophageal manometry has allowed the diagnosis of dysphagia before without organic lesions by endoscopy and radiology. Several treatments have been proposed but none is finally healing. Pneumatic dilation (PD) and surgical cardiomyotomy are treatments that allow prolonged remission [2].

We report in this study the experience of our service on the PD as an initial treatment of achalasia. We will determine the predictors of success and failure of this treatment.

\section{MATERIALS AND METHODS}

We included all adult patients (aged over 16 years) with nonobstructive dysphagia. Our inclusion criteria were: no organic causes in the Upper gastrointestinal endoscopy. In case of doubt we have performed chest and abdominal computed Tomography. An esophageal barium transit showing a mega-esophagus. Esophageal manometry confirming the diagnosis (impaired relaxation of the LES with swallowing and/or body aperistalsis of the esophagus).

Over a period of five years (between July 2002 and December 2007), 22 cases of achalasia were identified. Clinical, endoscopic, manometric, radiological (barium esophagram), therapeutic and evolutive data were collected. These data were analyzed using Epi Info software.

All patients fasted 12 hours prior pneumatic dilation after a final liquid meal. Dilations were performed without anesthesia. An upper gastrointestinal endoscopy performed just before allowed to suck the possible esophageal stasis, to verify the absence of mucosal injury and epiphrenic diverticulum that against this procedure. This also allowed endoscopy to place the guide wire. The material used is a balloon dilator Rigiflex (Microvasive, Milford, MA, USA) in polyethylene, $10 \mathrm{~cm}$ in length and 30,35 or $40 \mathrm{~mm}$ in caliber, a catheter $100 \mathrm{~cm}$ long. It slides along a metal guide wire in place during endo- 
scopy before the procedure.

The first dilatation is always performed with a balloon of $30 \mathrm{~mm}$ in diameter. Then, if necessary with progressive diameters 35 and $40 \mathrm{~mm}$. The balloon is inflated to a pressure of 10 psi, held for 30 seconds and then deflated in one minute each time, three times $(3 \times 30$ seconds $)$. The patients fasted 6 hours after the procedure; pulse and blood pressure were monitored every 2 hours.

Patients were routinely called a month later in consultation to assess the short-term results. The decision to perform a new expansion was based primarily on clinical criteria. Patients were asked about their current symptoms (frequency of dysphasia, chest pain, regurgitation, presence of respiratory signs, weight) and on the degree of improvement of symptoms after dilation. Success Criteria of the procedure was the decrease of Eckardt score, with a total score $\leq 2$, no items exceeding 2 . If patients were still symptomatic after the first expansion, we perform iterative pneumatic dilation. After three sessions of expansion, if symptoms persist we consider that it was a failure of pneumatic dilation and the patient was proposed to surgery.

\section{Statistical Analysis}

First, we conducted a clinical description of the different variables, endoscopic, radiological, manometric and therapeutic in our patients. In a second step, we performed univariate analyzes to study the effectiveness of the expansion in clinical symptoms and the factors influencing the clinical response (age, sex and initial Eckardt score). We used the Chi2 test for categorical variables and Student's t test for quantitative variables. A test was considered significant when $\mathrm{p}$ (significance level) was $<0.05$. Data entry and data analysis were performed using the Epi-Info software.

\section{RESULTS}

Twenty two patients with achalasia were included, they represented $0.47 \%$ of all patients in the Gastroenterology unit over a period of six years and six months. We excluded from our study one patient who had been treated by surgery immediately. Two patients were already known achalasic and were treated with cardiomyotomy performed 6 and 15 years ago.

The average age of patients was $44 \pm 10.66$ years $(20$ $76)$. The sex ratio was 1.3 for men $(12 \mathrm{H} / 9 \mathrm{~F})(\mathrm{p}=0.5)$. Symptoms had begun $36.8 \pm 34.8$ months $(3-120$ months) before diagnosis of achalasia. Dysphagia, the main symptom, was present in $100 \%$ of cases, chest pain were found in 13 cases $(62 \%)$, food regurgitation in 15 cases $(71.42 \%)$ and heartburn was noted in seven patients (33.33\%). Respiratory signs were present in $19.04 \%$ of cases, like aspiration ( 4 cases) and cough (one case).
Weight loss was reported in 10 patients $(47.61 \%)$ ranged from 6 to $16 \mathrm{~kg}$. The Eckardt clinical score averaged was $5.9 \pm 1.27$. Clinical examination objectified signs of malnutrition in two patients who reported a weight loss of 11 and $16 \mathrm{~kg}$ each. All of its general characteristics are summarized in Table 1. The endoscopy showed an appearance of dilated esophagus in $52 \%$ of cases $(n=11)$ and esophageal stasis in $90 \%(\mathrm{n}=19)$. The cardia was crossed with jump in $81 \%(n=17)$. In addition, three patients had a hiatal hernia and two cases of esophagitis were observed. Barium swallow esophageal (TO) was performed in 18 patients $(85.71 \%)$. The average esophageal diameter measured on this exam was $4.30 \pm 0.89$ $\mathrm{cm}$. Manometry was performed for only 16 patients $(76.2 \%)$ and showed complete aperistalsis of esophageal body in all patients $(100 \%)$ and a disorder of the relaxation of the LES in $93.75 \%(n=15)$ of cases. Mean follow-up after PD was $7.40 \pm 6.18$ months ( 1 - 28 months). Two patients $(9.5 \%)$ had reported heartburn after PD. No complications of dilatation were observed in our patients.

Thirty eight dilations were performed with an average PD of 1.8 per patient [1-6]. Remission after the third meeting of the PD was obtained in 19 patients $(90.47 \%)$ and no patient had relapsed. The good response rate from the fourth dilatation was $50 \%$. A fourth session was necessary in two other patients; remission was achieved in only one of them. The other patient who was 63 years old had received six sessions in total with symptomatic recurrence intervals of five months between the third, fourth and sixth expansion. These results showed that the rate of correct response after the third meeting of the PD was $90.47 \%$ (19 patients).

Table 1. Epidemiological and clinical characteristics of patients.

\begin{tabular}{lc}
\hline Parameters & Patients $(\boldsymbol{N}=\mathbf{2 1})$ \\
\hline Age (years) & $44 \pm 10.66$ \\
Sex $(M F)$ & 129 \\
Beginning of symptoms (months) & $50 \pm 43.26$ \\
History of myotomy (\%) & 9.5 \\
Dysphagia (\%) & 100 \\
Regurgitation (\%) & 71.42 \\
Chest pain (\%) & 62 \\
Respiratory manifestations $(\%)$ & 19.04 \\
Loss of weight (\%) & 47.61 \\
Eckardt score & $5.9 \pm 1.27$ \\
Average esophageal diameter $(\mathrm{cm})$ & $4.30 \pm 0.89$ \\
Pressure of LOS superior to $40 \mathrm{~cm} \mathrm{H}_{2} \mathrm{O}$ & $62.5 \%$ \\
\hline
\end{tabular}


To study the effectiveness of the PD on the clinical symptoms we compared the mean of Initial Eckardt score and one month after the third PD. The initial mean score was 5.90 and the average score after one month was 2.28 , the difference was highly significant $(\mathrm{p}=$ $0.000)$.

After univariate analysis, neither age nor sex nor the initial Eckardt score could be considered as predictive factors of failure of the PD $(p>0.05)$.

\section{DISCUSSION}

The different treatments of achalasia are palliative and aim to remove functional obstruction due to lack of relaxation of the LES to improve the quality of life for patients. Although understanding of the pathophysiological mechanisms of achalasia has progressed, pharmacological advances have been few, and medical therapy has a very modest place. According to a recent meta-analysis [2], pneumatic dilation and surgical cardiomyotomy are currently the two main treatments for achalasia that allow an early remission in $80 \%$ to $90 \%$ of cases. The objective of the PD is to create a pressure in order to suddenly dilacerate muscle of the lower esophagus, leaving intact the mucosa and serosa [2,3]. G.M. Campos et al. [2], in a recent meta-analysis of 15 studies of which eight were retrospective [4-11] and seven prospective [12-18] showed that the technique of balloon dilation was well codified in these lines (Table 2). Thus, the choice of balloon diameter differs from one operator to another. Some of them systematically used the smallest diameter ( 30 $\mathrm{mm})$ [4-8,10-16,19] during the first expansion, while others began with the balloon $35 \mathrm{~mm}[17,18]$. In our work we used the $30 \mathrm{~mm}$ balloon.

The inflation pressure ranged from $7[12,14]$ and 18 [5] psi, it was 10 psi in our work. The average inflation time was 73 seconds from six [16] to 240 [14] seconds. Gelfand et al. [12] were maintained, as in our study, the balloon inflated for 30 seconds. The number of sequences of inflation during the same dilatation varies from one to three different studies [15,20,21]. We also limited to three the number of sequences of PD during a single session.

The PD allows the improvement of symptoms in 56\% [15] 97\% [7] of patients assessed after one month. However, the effectiveness of the PD appears to decrease during follow-up of patients. Thus, it is around $76.8 \%$ at six months, from $68.2 \%$ at 12 months and $58.4 \%$ after 36 months follow-up [2]. In our study, $90.47 \%$ of patients were in remission three months after the PD.

The improvement of symptoms seems to depend on the diameter of the dilator, the duration of the PD and the number of PD [2]. K. Honein et al. [20] had achieved remission in $80.5 \%$ of cases after one or two dilatations. Concerning Diameter of the balloon, A. Dobrucali et al.

Table 2. Results of pneumatic dilation in achalasia.

\begin{tabular}{|c|c|c|c|c|c|c|c|}
\hline Autors & Year & Patients & Type of study & Balloon diameter (mm) & Pressure psi & Follow up months & Perforation \% \\
\hline Gelfand [12] & 1989 & 24 & Prospective & $30-35$ & 7 & 6 & 0 \\
\hline Barkin [5] & 1990 & 50 & Retrospective & $30-35-40$ & 18 & 15 & 8 \\
\hline Kadakia [13] & 1993 & 29 & Prospective & 30 & 8.8 & 48 & 0 \\
\hline Wehrmann [14] & 1995 & 40 & Prospective & $30-35$ & 7 & 29 & 3 \\
\hline Lambroza [6] & 1995 & 27 & Retrospective & $30-35-40$ & 15 & 21 & 0 \\
\hline Khan [16] & 1998 & 81 & Prospective & 30 & 10 & 6 & 0 \\
\hline Sabharwal [7] & 2002 & 76 & Retrospective & $20-30-40$ & - & 29 & 0 \\
\hline Mikaeli [17] & 2004 & 262 & Prospective & $30-35$ & 10 & 54 & 1 \\
\hline Guardino [4] & 2004 & 96 & Retrospective & 30 & 9.5 & 7 & 2 \\
\hline Dobrucali [15] & 2004 & 43 & Prospective & 30 & 15 & 28 & 2 \\
\hline Chan [8] & 2004 & 66 & Retrospective & $30-35-40$ & 9 & 55 & 5 \\
\hline Ghoshal [19] & 2004 & 126 & Retrospective & 30 & 11 & 15 & 1 \\
\hline Boztas [10] & 2005 & 50 & Retrospective & $30-35-40$ & - & 32 & 0 \\
\hline Katsinelos [11] & 2005 & 39 & Retrospective & $30-35-40$ & - & 111 & 5 \\
\hline Rai [18] & 2005 & 56 & Prospective & 35 & 10 & 6 & 0 \\
\hline Our study & 2008 & 21 & Retrospective & $30-35-40$ & 10 & 7.40 & 0 \\
\hline
\end{tabular}


[15] had noted a remission in 54\% of cases with $30 \mathrm{~mm}$ and $78 \%$ of cases with $35 \mathrm{~mm}$. Moreover, a good clinical response was observed in patients with lower sphincter pressure $\leq 10 \mathrm{~mm} \mathrm{Hg}$ of the esophagus after PD or in whom it has fallen by over $50 \%$ of the initial pressure $[11,22]$. In case of failure of the expansion, it is repeated several weeks later (four in our work) with a balloon of larger diameter. In case of repeated failures, most authors agree not to exceed three expansions [15,20,21] after which the patient was proposed for another treatment. The PD is currently the most effective endoscopic treatment of primary achalasia of the esophagus. The esophageal perforation is the most serious complication. However it is reported in only $1.6 \%$ of the average [2]. In our series, there was no perforation.

Surgical treatment of achalasia has evolved dramatically over the past 13 years. Since the first report of laparoscopic Heller myotomy in 1991 by Cuschieri [23] and thoracoscopic Heller myotomy by Pellegrini [24] in 1992, minimally invasive surgery has became the gold standard for the treatment of achalasia. More recently, the laparoscopic management of esophageal achalasia has achieved widespread acceptance and is now the first line of therapy for patients with achalasia. The satisfactory short-term results of this procedure are well documented in several large series [23-25]. In these studies, persistent postoperative dysphagia was observed in $10 \%$ to $30 \%$ of the patients. Patients with LES pressure $>35$ $\mathrm{mmHg}$ had more than 21 times the likelihood to achieve long term excellent relief of dysphagia after myotomy compared with those with LES pressure $\leq 35 \mathrm{mmHg}$. This finding probably means that patients with a low preoperative LES pressure did not get as much relief because their relative decrease in outflow obstruction is less.

\section{CONCLUSION}

Pneumatic dilation can be proposed as a first-line treatment of primary achalasia of the esophagus, it allows a short-term clinical remission in $90.47 \%$ of cases, and long-term in only 50\% supporting iterative expansions. Age was not predictive of poor response to the PD in our work; however, other studies are needed to confirm this result.

\section{REFERENCES}

[1] Spiess, A.E. and Kahrilas, P.J. (1998) Treating achalasia: From whalebone to laparoscope. The Journal of the American Medical Association, 28, 638-642. doi:10.1001/jama.280.7.638

[2] Campos, G.M. (2009) Endoscopic and surgical treatments for achalasia: A systematic review and meta-analysis. Annals of Surgery, 249, 45-57.

\section{doi:10.1097/SLA.0b013e31818e43ab}

[3] Bittinger, M. and Wienbeck, M. (2001) Pneumatic dilation in achalasia. Canadian Journal of Gastroenterology, 15, 195-199.

[4] Guardino, J.M., Vela, M.F., Connor, J.T. and Richter, J.E. (2004) Pneumatic dilation for the treatment of achalasia in untreated patients and patients with failed Heller myotomy. Journal of Clinical Gastroenterology, 38, 855860. doi:10.1097/00004836-200411000-00004

[5] Barkin, J.S., Guelrud, M., Reiner, D.K., Goldberg, R.I. and Phillips, R.S. (1990) Forceful balloon dilation: An outpatient procedure for achalasia. Gastrointestinal Endoscopy, 36, 123-126. doi:10.1016/S0016-5107(90)70964-9

[6] Lambroza, A. and Schuman, R.W. (1995) Pneumatic dilation for achalasia without fluoroscopic guidance: Safety and efficacy. American Journal of Gastroenterology, 90, 1226-1229.

[7] Sabharwal, T., Cowling, M., Dussek, J., Owen, W. and Adam, A. (2002) Balloon dilation for achalasia of the cardia: Experience in 76 patients. Radiology, 224, 719724. doi:10.1148/radiol.2243011049

[8] Chan, K.C., Wong, S.K., Lee, D.W., Mui, W.L., Chan, A.C., Ng, E.K., et al. (2004) Short-term and long-term results of endoscopic balloon dilation for achalasia: 12 years' experience. Endoscopy, 36, 690-694. doi:10.1055/s-2004-825659

[9] Ghoshal, U.C., Chaudhuri, S., Pal, B.B., Dhar, K., Ray, G. and Banerjee, P.K. (2001) Randomized controlled trial of intrasphincteric botulinum toxin A injection versus balloon dilatation in treatment of achalasia cardia. Diseases of the Esophagus, 14, 227-231. doi:10.1046/j.1442-2050.2001.00189.x

[10] Boztas, G., Mungan, Z., Ozdil, S., Akyüz, F., Karaca, C., Demir, K., et al. (2005) Pneumatic balloon dilatation in primary achalasia: The long-term follow-up results. Нераtogastroenterology, 52, 475-480.

[11] Katsinelos, P., Kountouras, J., Paroutoglou, G., Beltsis, A., Zavos, C., Papaziogas, B., et al. (2005) Long-term results of pneumatic dilation for achalasia: A 15 years' experience. World Journal of Gastroenterology, 11, 57015705 .

[12] Gelfand, M.D. and Kozarek, R.A. (1989) An experience with polyethylene balloons for pneumatic dilation in achalasia. American Journal of Gastroenterology, 84, 924927.

[13] Kadakia, S.C. and Wong, R.K. (1993) Graded pneumatic dilation using Rigiflex achalasia dilators in patients with primary esophageal achalasia. American Journal of Gastroenterology, 88, 34-38.

[14] Wehrmann, T., Jacobi, V., Jung, M., Lembcke, B. and Caspary, W.F. (1995) Pneumatic dilation in achalasia with a low-compliance balloon: Results of a 5-year prospective evaluation. Gastrointestinal Endoscopy, 42, 3136. doi:10.1016/S0016-5107(95)70239-3

[15] Dobrucali, A., Erzin, Y., Tuncer, M., Dirican, A., et al. (2004) Long-term results of graded pneumatic dilatation under endoscopic guidance in patients with primary eso- 
phageal achalasia. World Journal of Gastroenterology, 10, 3322-3327.

[16] Khan, A.A., Shah, S.W., Alam, A., Butt, A.K., Shafqat, F. and Castell, D.O. (1998) Pneumatic balloon dilation in achalasia: A prospective comparison of balloon distention time. The American Journal of Gastroenterology, 93, 1064-1067. doi:10.1111/j.1572-0241.1998.00330.x

[17] Mikaeli, J., Bishehsari, F., Montazeri, G., Yaghoobi, M. and Malekzadeh, R. (2004) Pneumatic balloon dilatation in achalasia: A prospective comparison of safety and efficacy with different balloon diameters. Alimentry Pharmacology \& Therapeutics, 20, 431-436.

[18] Rai, R.R., Shende, A., Joshi, A., Mathur, A. and Nijhawan, S. (2005) Rigiflex pneumatic dilation of achalasia without fluoroscopy: A novel office procedure. Gastrointestinal Endoscopy, 62, 427-431. doi:10.1016/j.gie.2005.04.008

[19] Ghoshal, U.C., Kumar, S., Saraswat, V.A., Aggarwal, R., Misra, A. and Choudhuri, G. (2004) Long-term follow-up after pneumatic dilation for achalasia cardia: Factors associated with treatment failure and recurrence. American Journal of Gastroenterology, 99, 2304-2310. doi:10.1111/j.1572-0241.2004.40099.x

[20] Honein, K., Slim, R., Yaghi, C., Kheir, B., Bou Jaoudé, J. and Sayegh, R. (2007) Pneumatic dilatation of achalasia:
Local experience in treating 41 patients. Lebanese Medical Journal, 55, 15-18.

[21] Harish, K., Harikumar, R., Kumar, S. and Thomas, V. (2007) Efficacy and safety of Rigiflex pneumatic dilation of achalasia under direct endoscopy. Indian Journal of Gastroenterology, 26, 96-97.

[22] Ponce, J., Garrigues, V., Pertejo, V., Sala, T. and Berenguer, J. (1996) Individual prediction of response to pneumatic dilation in patients with achalasia. Digestive Diseases and Sciences, 41, 2135-2141. doi:10.1007/BF02071392

[23] Shimi, S., Nathanson, L.K. and Cuschieri, A. (1991) Laparoscopic cardiomyotomy for achalasia. Journal of the Royal College of Surgeons of Edinburgh, 36, 152-154.

[24] Pellegrini, C., Wetter, L.A., Patti, M., et al. (1992) Thoracoscopic esophagomyotomy: Initial experience with a new approach for the treatment of achalasia. Annals of Surgery, 216, 291-296. doi:10.1097/00000658-199209000-00008

[25] Zaninotto, G., Annese, V., Costantini, M., et al. (2004) Randomized controlled trial of botulinum toxin versus laparoscopic Heller myotomy for esophageal achalasia. Annals of Surgery, 239, 364-370. doi:10.1097/01.sla.0000114217.52941.c5 